\title{
Step Training-Dependent Plasticity in Spinal Cutaneous Pathways
}

\author{
Marie-Pascale Côté and Jean-Pierre Gossard \\ Centre de Recherche en Sciences Neurologiques, Département de Physiologie, Faculté de Médecine, Université de Montréal, Montréal, Québec, H3C 3J7 \\ Canada
}

\begin{abstract}
Plasticity after spinal cord injury can be initiated by specific patterns of sensory feedback, leading to a reorganization of spinal networks. For example, proprioceptive feedback from limb loading during the stance phase is crucial for the recovery of stepping in spinal-injured animals and humans. Our recent results showed that step training modified transmission from group I afferents of extensors in spinal cats. However, cutaneous afferents are also activated during locomotion and are necessary for proper foot placement in spinal cats. We therefore hypothesized that step training would also modify transmission in cutaneous pathways to facilitate recovery of stepping. We tested transmission in cutaneous pathways by comparing intracellular responses in lumbar motoneurons $(n=136)$ in trained $(n=11)$ and untrained $(n=7)$ cats spinalized 3-5 weeks before the acute electrophysiological experiment. Three cutaneous nerves were stimulated, and each evoked up to three motoneuronal responses mediated by at least three different pathways. Overall, of 71 cutaneous pathways tested, 10 were modified by step training: transmission was reduced in 7 and facilitated in 3 . Remarkably, 6 of 10 involved the medial plantar nerve innervating the plantar surface of the foot, including two of the facilitated pathways. Because the cutaneous reflexes are exaggerated after spinalization, we interpret the decrease in most pathways as a normalization of cutaneous transmission necessary to recover locomotor movements. Overall, the results showed a high degree of specificity in plasticity among cutaneous pathways and indicate that transmission of skin inputs signaling ground contact, in particular, is modified by step training.
\end{abstract}

Key words: plasticity; treadmill training; cutaneous reflex pathways; locomotion; spinal; motor control

\section{Introduction}

Growing experimental and clinical findings provide evidence for activity-dependent plasticity of spinal networks (Wolpaw and Tennissen, 2001). These studies indicate that physiological, biochemical, and functional reorganization of lumbar spinal cord occur over time (Nacimiento et al., 1995; Edgerton et al., 1997a,b; Giroux et al., 1999). Consistent with this, strategies to recover motor functions after spinal cord injury (SCI) include the management of sublesional spinal cord based on the reorganization of the remaining undamaged neural pathways.

Sensory feedback plays a crucial role in the recovery of function after SCI in humans and animals. This is well illustrated by the ability to regain rhythmic locomotor patterns after repetitive sensory stimulation provided by step training (Lovely et al., 1986; Barbeau and Rossignol, 1987; Fung et al., 1990; DeLeon et al., 1998a; Harkema, 2001; Leblond et al., 2003). Improvement depends on specific activity-dependent sensory feedback (DeLeon et al., 1998b) and not on the effect of training on musculature (Roy and Acosta, 1986; Roy et al., 1999). For instance, step-

Received April 20, 2004; revised Nov. 3, 2004; accepted Nov. 5, 2004.

This work was supported by the Canadian Institutes of Health Research (CIHR) and the Christopher Reeve Paralysis Foundation. M.-P.C. was supported by a CIHR scholarship. We gratefully acknowledge A. Ménard for participating in the experiments and F. Lebel, I. Poulin, and C. Pepin for technical support.

Correspondence should be addressed to Dr. Jean-Pierre Gossard, Centre de Recherche en Sciences Neurologiques, Département de Physiologie, Faculté de Médecine, Université de Montréal, Case Postale 6128, Succursalle Centreville, Montréal, Québec, H3C 3J7 Canada. E-mail: jean-pierre.gossard@umontreal.ca.

DOI:10.1523/JNEUROSCI.1486-04.2004

Copyright $\odot 2004$ Society for Neuroscience ～0270-6474/04/2411317-11\$15.00/0 trained spinal cats improve their gait pattern but are not better at standing, and conversely, stand-trained animals are not better at stepping (DeLeon et al., 1998b, 1999). Also, functional stepping recovery and precise limb placement in spinal hemisected cats is correlated with sprouting of primary afferents (Helgren and Goldberger, 1993). Thus, both anatomical and behavioral evidence suggests that the sensory feedback can be used to compensate for the loss of supraspinal inputs to spinal circuits. However, little is known about the mechanisms and pathways underlying the beneficial action of sensory feedback.

Proprioceptive feedback during limb loading contributes to the recovery of stepping. In both humans and cats recovering from SCI, progressively increasing weight bearing improves stepping ability (Barbeau and Rossignol, 1987; Barbeau et al., 1987; Edgerton et al., 1992; Harkema et al., 1997). Moreover, we recently showed that step training modified transmission from group I afferents of extensors in spinal cats (Côté et al., 2003). However, cutaneous afferents are also activated by locomotor movements and may participate in recovery. Cutaneomuscular stimulation can partially restore normal reflex modulation in spastic SCI patients (Fung and Barbeau, 1994). Previous experiments showed that the selective phasic stimulation of cutaneous receptors from the plantar surface of the foot (without activation of proprioceptors signaling limb loading), was sufficient to permanently increase limb extension during swimming in spinal hemisected chicks (Muir and Steeves, 1997). Also, progressive cutaneous denervation of the hindlimb in spinal cats indicates 
that proper foot placement during stepping requires a minimum cutaneous input (Bouyer and Rossignol, 2003b). Because of its influence on locomotor networks, we hypothesized that step training would also modify transmission in cutaneous pathways. We tested this by comparing motoneuronal responses to cutaneous nerve stimulation in trained and untrained cats spinalized 3-5 weeks before an acute experiment. Our findings indicate that plasticity occurs only in specific cutaneous pathways, with decreased transmission detected in most. The results also reveal selective modification of skin inputs signaling ground contact, suggesting that plasticity of these connections may be of particular importance during step training.

\section{Materials and Methods}

All procedures were conducted according to the Guide for Care and Use of Experimental Animals (Canada), using protocols approved by the Ethics Committee of the Universite de Montréal.

Spinalization and locomotor training. Eighteen adult female cats (2.5$4.1 \mathrm{~kg}$ ) were used for this study. After administration of preoperative medication, the cats were anesthetized ( $2 \%$ isoflurane; Abbott Laboratories, Montréal, Québec, Canada) and spinalized at $\mathrm{T}_{13}$ under aseptic conditions. Protocols for spinalization procedures and subsequent postoperative care were analogous to those described previously (Chau et al., 1998a; Côté et al., 2003). A patch of fentanyl (Duragesic; $25 \mu$ g; JanssenOrtho, Markham, Ontario, Canada) was sutured on the back of the cat for continuous and stable delivery of analgesic over a $2 \mathrm{~d}$ period. The first group of cats was only spinalized [sham operated (sham)], whereas the second group was locomotor trained until they could support the weight of their hindquarters (mean, $28 \mathrm{~d}$ ). Training on the treadmill $(0.2-0.4$ $\mathrm{m} / \mathrm{sec}$ ) started $2 \mathrm{~d}$ after surgery and consisted of two to four daily training sessions for periods of $10 \mathrm{~min}$. In early training, hindquarters were supported by the experimenter to provide weight support, and perineal stimulation was used to increase central excitability and to maintain locomotion. The animal became gradually able to support its hindquarters and to walk, and perineal stimulation was no longer needed in most cases. No drugs were used to assist the locomotor training. The training was stopped when the cat was able to walk continuously on the treadmill for $>5$ min while the experimenter assisted only for lateral stability by holding the tail.

Acute experiment. Cats were first anesthetized by inhalation of an oxygenated mixture $(50 \%)$ of nitrous oxide $(50 \%)$ and halothane $(2-3 \%$; MTC Pharmaceuticals, Cambridge, Ontario, Canada). Cannulas were inserted in the right common carotid artery to monitor blood pressure and in the jugular and cephalic veins for administration of pharmacological agents or fluids. Cats were then decerebrated and curarized (Pavulon; $0.2 \mathrm{mg} / \mathrm{kg} / 45 \mathrm{~min}$; Sabex, Boucherville, Ontario, Canada) and artificially ventilated as detailed previously (Ménard et al., 1999; Leblond et al., 2000).

To monitor locomotor episodes and antidromically identify motoneurons, the following muscle nerves from the left hindlimb were dissected free, cut, and mounted on bipolar silver chloride electrodes for recording [electroneurogram (ENG)] and stimulation: posterior bicepssemitendinosus (PBSt), semimembranosus-anterior biceps (SmAB), lateral gastrocnemius-soleus (LGS), medial gastrocnemius (MG), plantaris (Pl), flexor hallucis longus (FHL) and flexor digitorum longus (FDL) together, tibialis anterior (TA), extensor digitorum longus (EDL), and sciatic nerve (uncut). Three cutaneous nerves were also dissected free for subsequent stimulation: caudal cutaneous sural (CCS), medial plantar (MPL), and superficial peroneal (SP).

Stimulation, recordings, and analysis. The cord dorsum potential (CDP) was recorded with a silver chloride ball electrode located near the dorsal root entrance at the L6-L7 border. Stimulation intensity required to just evoke a deflection in the CDP determined the threshold for the most excitable fibers for each nerve (1T). Stimulus intensity was expressed as a multiple of the threshold. Intracellular potentials evoked by the stimulation of low-threshold cutaneous afferents (CCS, MPL, SP; one pulse; $2 \mathrm{~T}$ ) were recorded in identified extensor and flexor/bifunctional motoneurons (Leblond et al., 2000) with glass micropipettes filled with
$\mathrm{K}^{+}$-acetate (2 M) and QX314 [N-(2,6-dimethylphenylcarbamoylmethyl) triethylamonium bromide; $100 \mathrm{~mm}$; Alamone Laboratories, Jerusalem, Israel] to prevent sodium spikes. FDL and FHL motoneurons could be distinguished by their responses to SP stimulation and the phase of peak depolarization during fictive stepping (Burke, 1999). The duration of the afterhyperpolarization (AHP) was measured in every cell, from the spike onset to where the AHP crosses the baseline (Gustafsson and Pinter, 1984). Stimulation of peripheral nerves was given every $0.3,0.4$, or $0.5 \mathrm{sec}$.

All responses were further studied during a period of $2 \mathrm{hr}$ after intravenous clonidine injection ( $\alpha_{2}$-noradrenergic agonist; $500 \mu \mathrm{g} / \mathrm{kg}$; Sigma, St. Louis, MO) and during episodes of fictive locomotion induced by perineal stimulation. Up to two doses of clonidine were injected in an experiment, and data were recorded for the following $2 \mathrm{hr}$. Once clonidine was injected, there was no return to control conditions, and all subsequent recordings were considered post-clonidine data.

A "trial" is the averaged response in one motoneuron evoked by the stimulation $(n \geq 40)$ of a given pathway (a cutaneous afferent-motoneuron pair). Several pathways could be studied in a given motoneuron corresponding to different cutaneous stimulation. The transmission of cutaneous pathways was monitored by measuring the peak amplitude of IPSP and EPSP in motoneurons. The amplitude of IPSPs (R2) was measured as the maximal negative deflection from the baseline in the intracellular trace in response to the stimulation, and the amplitude of EPSPs (R1-R3) was measured as the maximal positive deflection from the baseline, as illustrated in Figure 2 (upward and downward arrows) and described in Results. Changes attributable to training, clonidine, or locomotion were determined by comparing the average amplitude obtained in each of these three conditions.

Data collected during rest (silent ENGs) and during fictive stepping were compared to study state-dependent changes in cutaneous transmission. During locomotor episodes, bursts of ENG activities were used to divide the step cycle into flexion (corresponding to swing) and extension (corresponding to stance) phases. The locomotor cycle, defined as the period between the onsets of two successive bursts of ENG activity in extensors, was normalized to the duration of the averaged cycle. PSPs evoked during flexion and extension were separated and averaged to study phase-dependent modulation.

Statistical analysis. Histograms in the figures are expressed as means \pm SEM. Statistical analysis was performed to disclose differences between responses obtained (1) in sham-operated and trained groups (trainingdependent plasticity), (2) at rest and during fictive locomotion (statedependent changes), (3) during flexion and extension phases of locomotion (phase-dependent changes), and (4) before and after clonidine injection. The Kolmogorov-Smirnov-Liliefors test was used to compare the shape and location of the distribution of responses to a normal distribution, and the Levene median test was used for equal variance. If these two tests confirmed that the sample variables did fit a normal distribution and were equally variant, a one-way ANOVA was performed; if not, the Kruskal-Wallis one-way ANOVA on ranks was used. The $\chi^{2}$ with the Yates correction factor or Fisher's exact test evaluating frequency distributions was used to further identify differences in the occurrence of type of responses between groups. For all statistical tests, the significance level was set to $p<0.05$. In histograms, significant difference is indicated as follows: ${ }^{\star} p<0.05 ;{ }^{* *} p<0.01$; or ${ }^{* * *} p<0.001$. When no significant changes were found in data measured before and after clonidine injection, the data were merged together.

\section{Results}

In the first section, we present the effect of training on response amplitude recorded at rest and during fictive locomotion episodes. In the next section, we compare response amplitude between locomotion versus rest in shams and also in trained cats. In the last section, the effect of clonidine is compared with the effect of training. In each section, changes in the transmission of cutaneous pathways were monitored by measuring the peak amplitude of IPSPs and EPSPs in several motoneurons. AHP duration, which varies systematically with input resistance and membrane time constant (Gustafsson and Pinter, 1984), was compared be- 
a

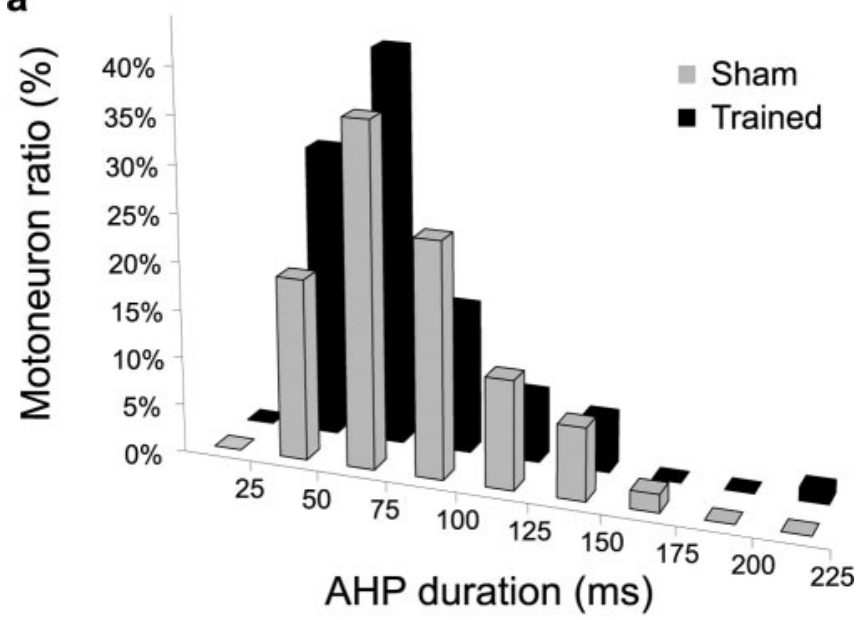

b

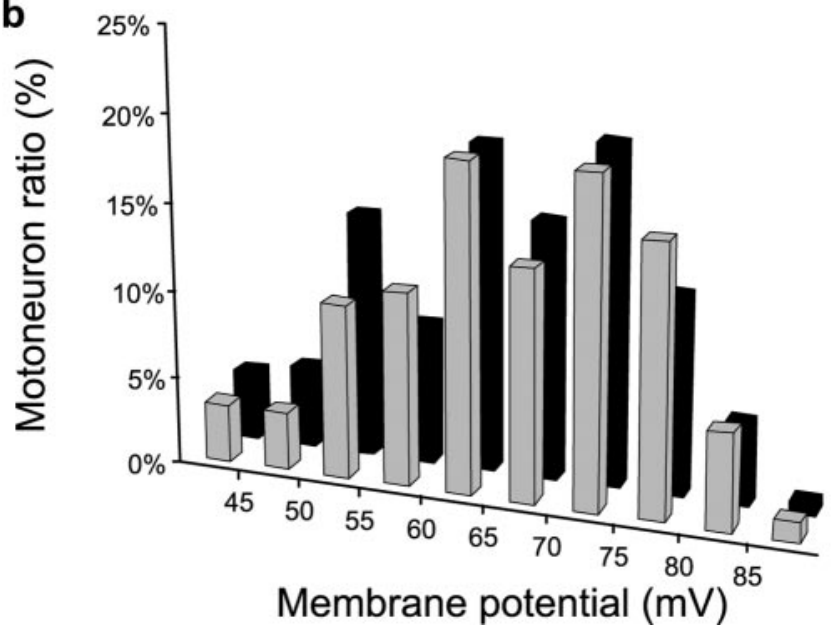

Figure 1. Training did not modify AHP duration and membrane potential. The histograms of AHP duration ( $a$ ) and membrane potential $(b)$ of motoneurons in shams (gray) and trained cats (black) show a similar distribution.

tween sham and trained cats as an indication of the size and membrane resistance of motoneurons. Figure $1 a$ shows the similarity of AHP duration distribution for both groups of cats. Overall, there was no significant difference between mean AHP duration ( $\pm \mathrm{SE}$ ) measured in the two groups of cats (sham, $76 \pm$ $4.3 \mathrm{msec}$; trained, $68 \pm 3.7 \mathrm{msec}$ ), even if grouped according to the motor pool (data not shown). Also, a change in PSP amplitude could be partly attributable to differences in membrane potential (Coombs et al. 1955; Powers and Binder, 1985). We therefore compared the levels of membrane potential at rest of all motoneurons of shams (average, $62.1 \pm 1.1 \mathrm{mV}$ ) and trained cats (average, $60.5 \pm 0.9 \mathrm{mV}$ ) and found no significant difference ( $p=0.24$ ). Figure $1 b$ shows the similarity of membrane potential distribution for both groups of cats.

\section{Cutaneous PSP patterns}

We evaluated the effect of training on patterns of PSPs evoked by cutaneous afferents recorded at rest in five extensor (22 FHL, 17 MG, 16 SmAB, 15 LGS, 12 Pl) and three flexor/bifunctional (21 PBSt, 20 EDL, 13 FDL) motoneuronal pools of 7 shams and 11 trained cats. Figure 2 illustrates six different patterns of PSPs elicited by a single shock in cutaneous afferents in various motoneurons. These multiphasic records were typical of the effects a Type A response

b

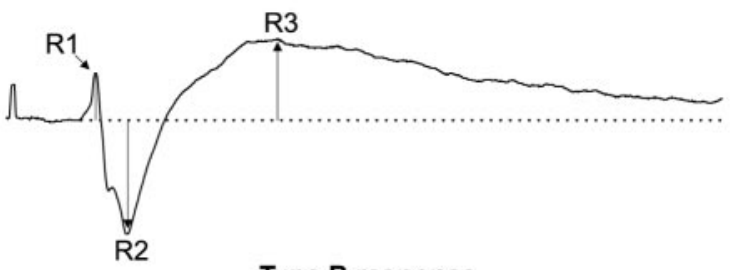

Type $B$ response

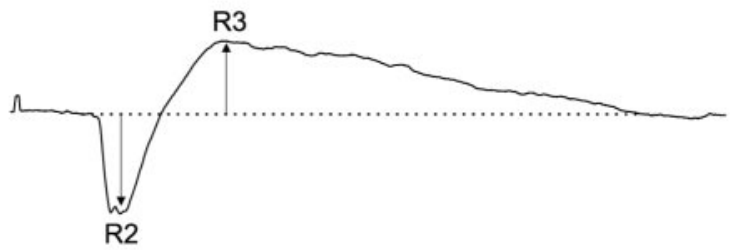

C

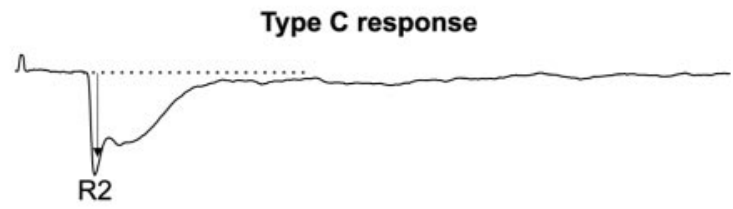

Type $\mathrm{D}$ response

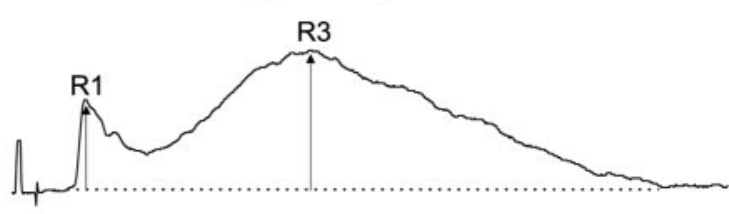

e

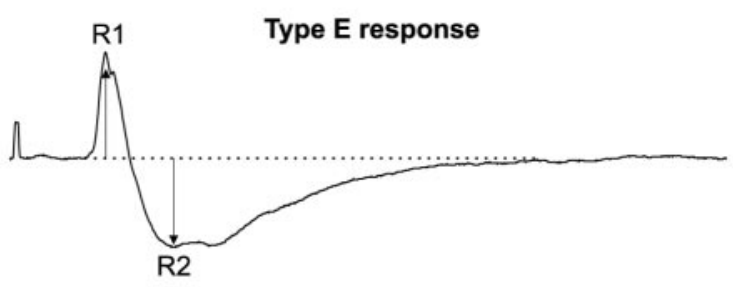

f

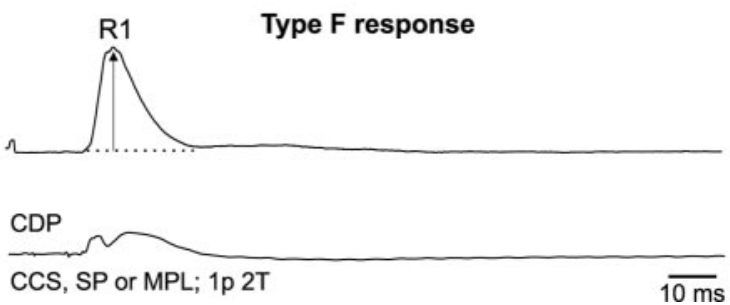

Figure 2. Type of responses to cutaneous stimulation recorded in motoneurons. Representative averaged PSP patterns ( $n \geq 62$ ) evoked by cutaneous afferents (CCS, MPL, or SP) recorded in extensor or flexor/bifunctional motoneurons are shown. The initial depolarization is referred to as $R 1$, the subsequent hyperpolarization referred to as $R 2$, and the following depolarization referred to as R3. $a$, Type A response: $\mathrm{R} 1-\mathrm{R} 2-\mathrm{R} 3 ; \boldsymbol{b}$, type B response: $\mathrm{R} 2-\mathrm{R} 3$; $c$, type $\mathrm{C}$ response: $\mathrm{R} 2$; $d$, type $\mathrm{D}$ response: $\mathrm{R} 1-\mathrm{R} 3$; $e$, type $\mathrm{E}$ response: $\mathrm{R} 1-\mathrm{R} 2 ; f$, type $\mathrm{F}$ response: $\mathrm{R} 1$. Baseline is represented by a dotted line from which amplitude is measured for each component (upward and downward arrows). Calibration pulse, $1 \mathrm{mV}$.

observed intracellularly. Responses were composed of one to three components: early excitation (R1), inhibition (R2), and late excitation (R3) (Baker and Chandler, 1987b). More precisely, type A response was composed of R1-R2-R3 (Fig. 2a), type B 
Table 1. Effect of training on the type of responses to cutaneous stimulation according to motoneuronal pool

\begin{tabular}{|c|c|c|c|c|c|c|c|c|c|c|c|c|c|c|c|c|c|}
\hline & \multicolumn{2}{|c|}{$\mathrm{FHL}$} & \multicolumn{2}{|c|}{ LGS } & \multicolumn{2}{|c|}{ MG } & \multicolumn{2}{|c|}{ SmAB } & \multicolumn{2}{|c|}{$\mathrm{PI}$} & \multicolumn{2}{|c|}{ EDL } & \multicolumn{2}{|c|}{ FDL } & PBSt & \multicolumn{2}{|c|}{ TOTAL } \\
\hline & Sham & Trained & Sham & Trained & Sham & Trained & Sham & Trained & Sham & Trained & Sham & Trained & Sham & Trained & Sham Trained & Sham & Trained \\
\hline & $n=23$ & $n=31$ & $n=15$ & $n=25$ & $n=21$ & $n=28$ & $\mathrm{n}=16$ & $n=27$ & $n=22$ & $n=11$ & $n=12$ & $n=38$ & $n=12$ & $n=26$ & $n=24 \quad n=28$ & $n=145$ & $n=214$ \\
\hline Type A (R1-R2-R3) & $78.3 \%$ & $67.7 \%$ & $100.0 \%$ & $72.0 \%$ & $61.9 \%$ & $42.9 \%$ & $75.0 \%$ & $70.4 \%$ & $63.6 \%$ & $63.6 \%$ & $50.0 \%$ & $57.9 \%$ & $100.0 \%$ & $61.5 \%$ & $25.0 \% 17.9 \%$ & $66.2 \%$ & $56.1 \%$ \\
\hline Type B (R2-R3) & $8.7 \%$ & $9.7 \%$ & & $8.0 \%$ & $19.0 \%$ & $3.6 \%$ & & & & $27.3 \%$ & $8 . \overline{3} \%$ & $2.6 \%$ & & & & $4.8 \%$ & $4.7 \%$ \\
\hline Type C (R2) & $4.3 \%$ & $3.2 \%$ & & & & & & & $9.1 \%$ & & & & & & & $2.1 \%$ & $0.5 \%$ \\
\hline Type D (R1-R3) & $8.7 \%$ & $19.4 \%$ & & $16.0 \%$ & $19.1 \%$ & $50.0 \%$ & $25.0 \%$ & $18.5 \%$ & $18.2 \%$ & $9.1 \%$ & $25.0 \%$ & $36.9 \%$ & & $30.8 \%$ & $41.7 \% \mathbf{7 1 . 4 \%}$ & $18.6 \%$ & $33.6 \%$ \\
\hline Type E (R1-R2) & & & & $4.0 \%$ & & & & $7.4 \%$ & $9.1 \%$ & & $8 . \overline{3} \%$ & $2.6 \%$ & & $7.7 \%$ & $8.3 \%$ & $3.5 \%$ & $2.8 \%$ \\
\hline Type F (R1) & & & & & & $3.5 \%$ & & & & & & & & & $25.0 \% \quad 10.7 \%$ & $4.1 \%$ & $1.8 \%$ \\
\hline No response & & & & & & & & $3.7 \%$ & & & $8 . \overline{3} \%$ & & & & & $0.7 \%$ & $0.5 \%$ \\
\hline
\end{tabular}

The proportion of the type of responses evoked by cutaneous stimulation (CCS, MPL, and SP) is reported according to the motor pool (extensor: FHL, LGS, MG, SmAB, and Pl; flexor/bifunctional: EDL, FDL, and PBSt) in shams and trained cats. The number of observations or trials $(n)$ for a given type is expressed as the percentage of the total trials recorded in that motor pool in shams or in trained cats. The most represented type is highlighted in gray for shams and in black for trained cats. Note that the training did not modify the distribution of types of cutaneous responses evoked in most motor pools. Training did change the distribution of responses evoked in FDL motoneurons ( $p<0.05$ ) with the appearance of type D and type E responses (dotted square).

response was composed of R2-R3 (Fig. $2 b$ ), type $\mathrm{C}$ response was composed of R2 (Fig. $2 c$ ), type D response was composed of R1-R3 (Fig. 2d), type E response was composed of R1-R2 (Fig. $2 e$ ), and type F response was composed of R1 (Fig. $2 f$ ). The relative frequency of type A-F responses is reported in Table 1. As noted in previous reports (Baker and Chandler, 1987b), the most represented type of response was composed of all three components (i.e., the pattern referred to as type A here). In shams, the type A response was most prevalent in seven of eight motoneuronal pools, except for PBSt (Table 1, gray highlight), whereas in trained cats, the type A response was most prevalent in six of eight motoneuronal pools (Table 1, black highlight), except for MG and PBSt. In those two cases, type D response (R1-R3) was the most prevalent. We then performed an analysis of frequency of type A-F responses to assess the effect of training. Overall, training did not modify the distribution of the different types of responses (Table 1), the type A response being the most common finding in both groups (66.2\% sham, $56.1 \%$ trained). Also, the type A response was the most represented type in both extensor (74.2\% sham, $63.1 \%$ trained) and flexor/bifunctional $(50.0 \%$ sham, $46.7 \%$ trained) motoneurons. When grouped according to motoneuronal pools, training tended to increase the occurrence of type D responses in six of eight motor pools. However, only the distribution of responses recorded in FDL motoneurons was significantly modified by training $(p<0.05)$; the type A response was recorded in $100 \%$ of trials in shams, whereas in addition to type A, both types D and $\mathrm{E}$ were recorded in trained cats (Table 1 ). Type D has no inhibitory response (R2), and this absence is not simply attributable to a difference in membrane potential levels in FDL motoneurons between shams (average, $71.0 \pm 3.3$ $\mathrm{mV}$ ) and trained cats (average, $61.4 \pm 3.9 \mathrm{mV} ; p=0.16$ ).

Because the type A response was the most common finding both in shams and in trained cats, as reported for chronic and acute spinal cats (Baker and Chandler, 1987b), the amplitude of all three components were collected for additional analysis. Here the three components were considered as the outcome of three different pathways involving a different number of interneurons inserted between cutaneous afferents and motoneurons (Pinter et al., 1982). Data were pooled according to motor nuclei and stimulated cutaneous nerve (see below). The mean amplitude for each of the three components was compared between sham and trained cats. The absence of one of the components (Fig. $2 b-f$ ) was considered as $0 \mathrm{mV}$ of amplitude for that component and $100 \%$ reduction in synaptic transmission in that pathway.

\section{Effect of training recorded at rest}

Significant changes in transmission in cutaneous pathways attributed to training were calculated by comparing data measured in the sham and trained groups. Table 2 depicts the effect of training on cutaneous responses evoked by CCS, MPL, or SP in various extensor and flexor/bifunctional motoneuronal pools. Among all the possible afferent-motoneuron pairs, we succeeded in testing 71 of 72 . Of the 71 pathways tested at rest, 10 were significantly modified by training. In a majority of these cases ( 7 of 10), training decreased the mean amplitude of responses. Each cutaneous source tested was significantly modified in at least one pathway, and MPL was the most potent (6 of 10 pathways). Training barely affected the amplitude of R2 (2 of 10). Also, when significantly modified by training, R3 amplitude was reduced in extensor motor pools (CCS-MG-R3, MPL-MG-R3) and increased in flexor/bifunctional motor pools (CCS-EDL-R3, MPLPBSt-R3). Data from several cats were used to reveal the modifications attributable to training on pathways to MG (4-5 cats), $\mathrm{Pl}$ (3-5 cats), EDL ( $8-12$ cats), and PBSt (7-11 cats) motor pools.

The effect of training was predominantly observed in MG motoneurons. Of the 10 pathways significantly modified, six had MG as a target (Table 2). Actually, training significantly modified the mean amplitude of the responses in six of nine pathways recorded in MG motoneurons as reported in Table 2. All significant changes were a decrease in amplitude (Fig. $3 a-c$ ) (CCSMG-R1, MPL-MG-R2, SP-MG-R2, CCS-MG-R3, MPL-MGR3), except for MPL-MG-R1, which increased in amplitude (Fig. $3 b$ ). Moreover, one should note that training reduced $\mathrm{R} 2$ amplitude only in MG motoneurons (MPL-MG-R2, SP-MG-R2). This training-induced reduction in the amplitude of R2 in MG motoneurons was not attributable to a reduced occurrence of inhibition. As noted above, a change in IPSP amplitude could also be attributable to a difference in membrane potentials in the two groups. We therefore analyzed the relationship between IPSP amplitude and membrane potential levels in all MG cells and found no significant linear relationship [as did Powers and Binder (1985) $]$ in shams $(r=0.20 ; p=0.45)$ or trained cats $(r=$ $0.50 ; p=0.08)$. Restricting comparisons to cells with membrane potential between $50-65$ and $65-80 \mathrm{mV}$ did not eliminate differences in IPSP amplitude either.

It was reported before that cutaneous stimulation produced a differential distribution of early EPSPs (referred to as R1 here) within the three extensor motor nuclei comprising the triceps surae in decerebrate cats (LaBella et al., 1989), semichronic spinal cats (LaBella et al., 1992), and humans (Duysens et al., 1996). 
Table 2. Effect of training on the mean amplitude of responses in specific cutaneous pathways

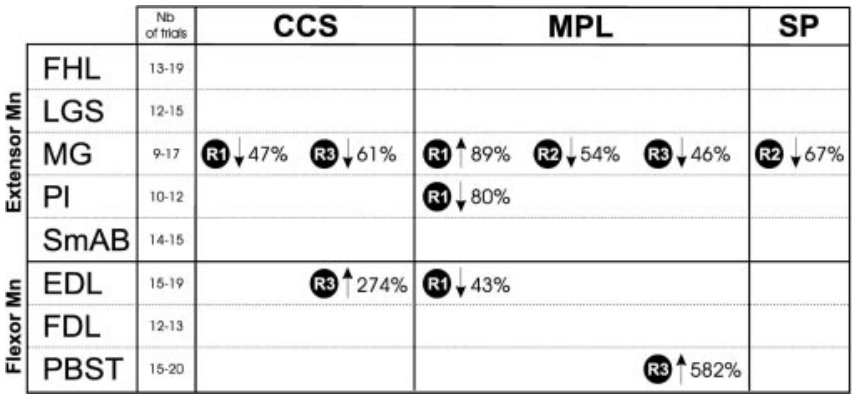

The effect of training is reported according to the afferents (CCS, MPL, and SP) and motoneurons (FHL, LGS, MG, PI, SmAB, EDL, FDL, and PBSt). Pathways (R1, R2, or R3) significantly modified (10 of 71 tested pathways) by training are represented as circled numbers. Upward arrows indicate an increase and downward arrows indicate a reduction in mean amplitude between shams and trained cats. These are followed by the mean percentage of change in amplitude as calculated by comparing the mean amplitude (on the basis of all trials) obtained in trained cats to the one obtained in shams. The number of trials for each pathway for the corresponding motor pool is shown in the second column.

CCS afferent stimulation preferentially evoked excitation in MG motoneurons, whereas SP afferents preferentially evoked excitation in LG (LaBella et al., 1989, 1992). We therefore tested whether the differential distribution of PSPs in MG and LGS motoneurons was maintained both in chronic spinal shams and trained cats. In agreement with these previous reports, the amplitude of R1 evoked by CCS was greater in MG than in LGS both in shams $(p<0.05)$ and in trained cats $(p<0.001)$. In addition, we further looked at R2 and R3 amplitude. R2 amplitude was smaller in MG than in LGS in trained cats $(p<0.01)$ but not in shams, whereas R3 amplitude was greater in MG than in LGS in shams $(p<0.01)$ but not in trained cats. Also, CCS afferent stimulation more frequently produced responses without R2 (type D) in MG than in LGS in shams $(p<0.05)$ but not in trained cats. The results suggest that CCS afferents are more likely to transmit excitation (early and late) to the MG than LGS motor pool and that no dramatic difference was observed because of training. However, training did change the differential excitation from SP afferents to MG and LGS motoneurons. As in decerebrate cats (LaBella et al., 1992), R1 amplitude was more frequently absent in MG than in LGS motoneurons in shams $(p<0.05)$ (LaBella et al., 1992). Conversely, in trained cats, R2 amplitude was more often absent in MG than in LGS motoneurons $(p<0.05)$.

\section{Locomotion versus rest in sham and trained cats}

As shown in other pathways (Conway et al., 1987; Gossard et al., 1994; McCrea et al., 1995), modification in cutaneous transmission could emerge only during the operation of locomotor networks. We therefore evaluated state-dependent changes in the transmission of cutaneous pathways by comparing responses recorded at rest and during fictive locomotion both in shams and in trained cats. Intracellular recordings during locomotor episodes (either spontaneous or after perineal stimulation) and rest were performed in five extensor (13 MG, $10 \mathrm{FHL}, 10 \mathrm{SmAB}, 6 \mathrm{LGS})$ and one flexor (10 EDL) motor pools of six shams and seven trained cats. Among all possible afferent-motoneuron pairs, we succeeded in testing 38 of 45 pathways both in shams and in trained cats.

Table $3 a$ depicts the effect of locomotion obtained without drugs on cutaneous responses evoked either by CCS, MPL, or SP in various motor pools in shams and trained cats. More pathways were modified during locomotion in shams (13 of 38) compared with trained cats $(4$ of $38 ; p<0.05)$. The amplitude of most of
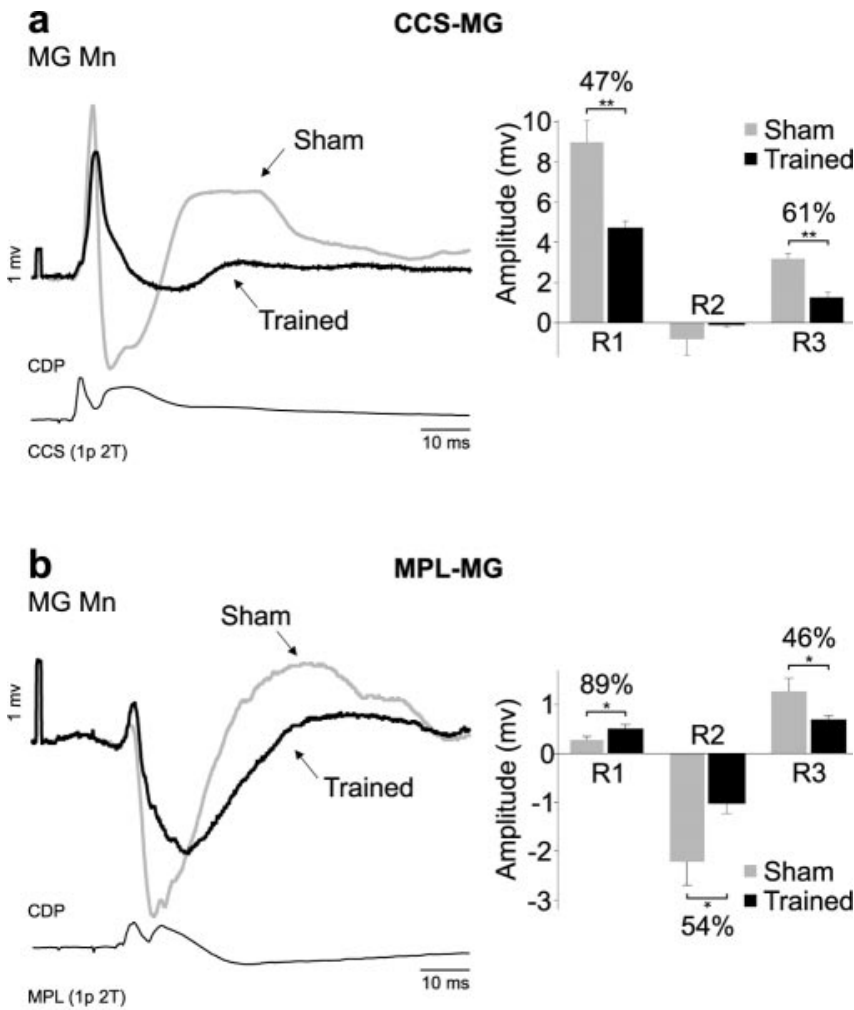

C

MG Mn
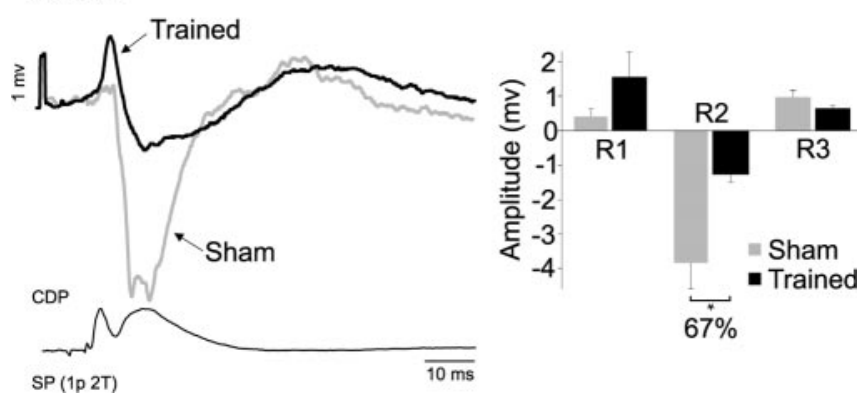

Figure 3. Training specifically modified transmission from cutaneous afferents to the MG motor pool. Left, PSPs $(n \geq 40)$ evoked by stimulation of CCS (a), MPL (b), and SP ( $c$ ) afferents recorded in MG motoneurons with similar AHPs (range, $70-91 \mathrm{msec}$ ) in a sham (gray) and a trained cat (black). Right, Histograms of the mean amplitude of responses evoked by $\operatorname{CCS}(a)$, $M P L(b)$, and SP (c) afferents recorded in all MG motoneurons in shams (gray) and trained cats (black). Six of the nine pathways tested in MG motoneurons were modified by training. Significant differences are indicated as follows: ${ }^{*} p<0.05 ;{ }^{* *} p<0.01$. Overall, training decreased both CCS-MG-R1 (by 47\%) and CCS-MG-R3 (by 61\%) (a) amplitude, increased MPL-MG-R1 amplitude (by 89\%), decreased MPL-MG-R2 (by 54\%) and MPL-MG-R3 (by 46\%) (b) amplitude, and decreased SP-MG-R2 amplitude (by 67\%) (c). Mn, Motoneuron.

these 17 responses decreased during locomotor episodes ( 10 of 13 shams, 3 of 4 trained), except for MPL-MG-R1, SP-MG-R1, and CCS-EDL-R3 in shams and CCS-MG-R2 in trained cats. Again, change in transmission from cutaneous afferents to MG motoneurons was the major modification caused by locomotion ( 6 of 13 shams, 2 of 4 trained). Note that R2 amplitude was rarely modified by locomotor networks in shams (2 of 13) compared with trained cats ( 3 of 4 ). Altered transmission in pathways originating from CCS afferents was the major modification in shams (6 of 13), whereas those originating from CCS (2 of 4 ) and SP (2 of 4) afferents exhibited the largest changes in trained cats. 


\section{Effect of training during fictive locomotor episodes}

We also assessed the effect of training by comparing responses obtained during locomotor episodes in two to five shams and two to nine trained cats depending on pathways. We first compared the overall amplitude evoked by a given pathway during entire locomotor episodes in shams or trained cats. Of the 31 pathways tested during locomotor episodes, training reduced transmission in only two: CCSMG-R1 and SP-MG-R1 (data not shown)

We then analyzed whether training modified the phase-dependent modulation pattern of cutaneous transmission. Transmission through cutaneous reflexes is modulated in a phase-dependent manner during the locomotor step cycle in intact cats (Forssberg et al., 1975; Drew and Rossignol, 1987) as well as during fictive stepping in immobilized, decerebrate semichronic (LaBella et al., 1992) and chronic (Forssberg et al., 1975, 1977; Andersson et al., 1978) spinal cats. Overall, we found that, when significantly modulated during the fictive step cycle, SPEPSPs and CCS-EPSPs (R1) were of maximal amplitude during flexion in a majority of cases both in flexors/bifunctional (5 of 6) and in extensors (20 of 23), whereas MPL-EPSPs (R1) were of maximal amplitude in extension both in flexors/bifunctional (9 of 9) and in extensors (2 of 4). Moreover, contrary to previous reports (Andersson et al., 1978; Schomburg and Behrends, 1978), the maximum amplitude of SP-IPSPs, MPL-IPSPs, and CCSIPSPs (R2) occurred during the extension phase in extensors (39 of 44) and during the flexion phase in flexors/bifunctional motoneurons ( 6 of 6). For example, in Figure 4 we superimposed the averaged responses to CCS stimulation in a MG motoneuron evoked during the depolarized (gray traces) and the hyperpolarized (black traces) phases of the fictive step cycle in a sham (Fig. $4 a$ ) and in a trained cat (Fig. $4 b$ ). The amplitude of the IPSP in both cases was increased during the depolarized phase. As mentioned above, the IPSP amplitude (R2) could depend on variations in membrane potentials. Figure $4 c$ shows the R2 amplitude plotted against the locomotor-drive potential (LDP) amplitude for all motoneurons, and there was no linear relationship between these two values neither in shams $(r=0.41)$ nor in trained cats $(r=0.48)$. We also found that training did not significantly modify the peak-to-peak amplitude of LDPs (data not shown). Overall, there were no significant differences in the ratio of cells significantly modulated, in the phase-dependency patterns or in the depth of modulation between shams and trained cats.

\section{Effect of clonidine}

Clonidine is an $\alpha_{2}$-noradrenergic agonist known to improve the initiation and modulation of locomotor patterns, to accelerate locomotor recovery in chronic spinal cats (Barbeau et al., 1987; Barbeau and Rossignol, 1991; Chau et al., 1998a), and to facilitate the emergence of fictive walking patterns (Forssberg and Grillner, 1973; Pearson and Rossignol, 1991). Moreover, reduced spastic- ity and facilitation of locomotor recovery was seen in two SCI subjects after clonidine and cyproheptadine (serotoninergic antagonist) treatment (Fung et al., 1990). Clonidine also reduced spasticity dramatically in eight SCI subjects and improved gait patterns in three subjects (Rémy-Néris et al., 1999). Overall, two to five shams and two to eight trained cats were used to test the effect of clonidine on pathways ending on the different motor pools. In most cases, we compared responses from motoneurons recorded before drug injection with those from motoneurons recorded after injection. However, we succeeded in maintaining intracellular recordings of seven motoneurons while injecting clonidine and had the opportunity to follow changes in cutaneous responses. In Figure 5, we compared responses in five of these motoneurons (superimposed traces) obtained before (gray) and after (black) clonidine injection. The mean amplitude of the overall population of motoneurons (before and after injection) is reported as histograms. For example, SP-FHL-R2 amplitude was decreased by clonidine in an FHL motoneuron in a sham cat (Fig. $5 a$, traces), and MPL-FHL-R2 amplitude was also decreased in an FHL motoneuron in a trained cat (Fig. $5 b$, traces). The membrane potential in the same motoneuron did not change after clonidine injection. Note that the decrease in R2 amplitude was also significant in the overall FHL population of shams (Fig. $5 a$, histogram) and trained cats (Fig. 5b, histogram). There was also an increase in MPL-FHL-R1 amplitude attributable to clonidine in FHL motoneurons of shams (Fig. 5a, histograms). The effects of clonidine on SP-, MPL-, and CCS-evoked PSPs are also illustrated in one MG motoneuron of a trained cat (Fig. $5 c-e$ ). Only SP-MG-R2 


\section{a}

\section{MG Mn}

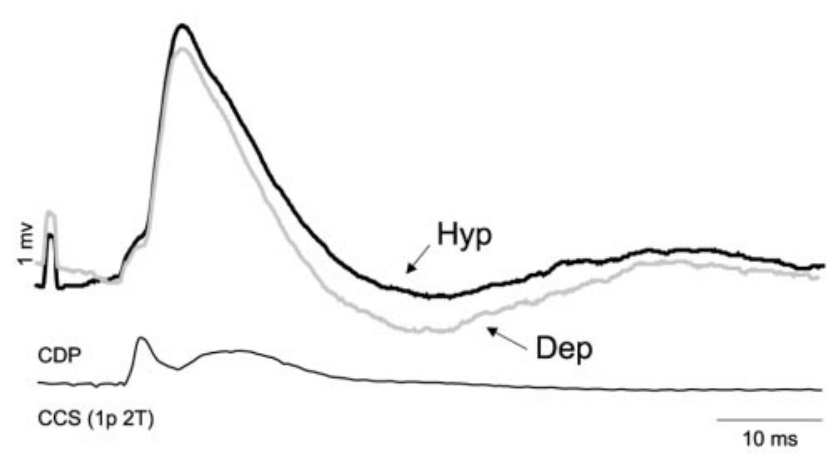

b MG Mn

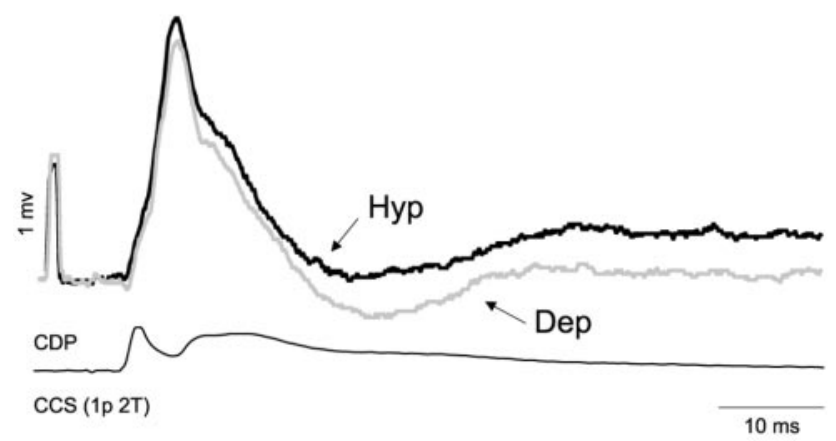

C

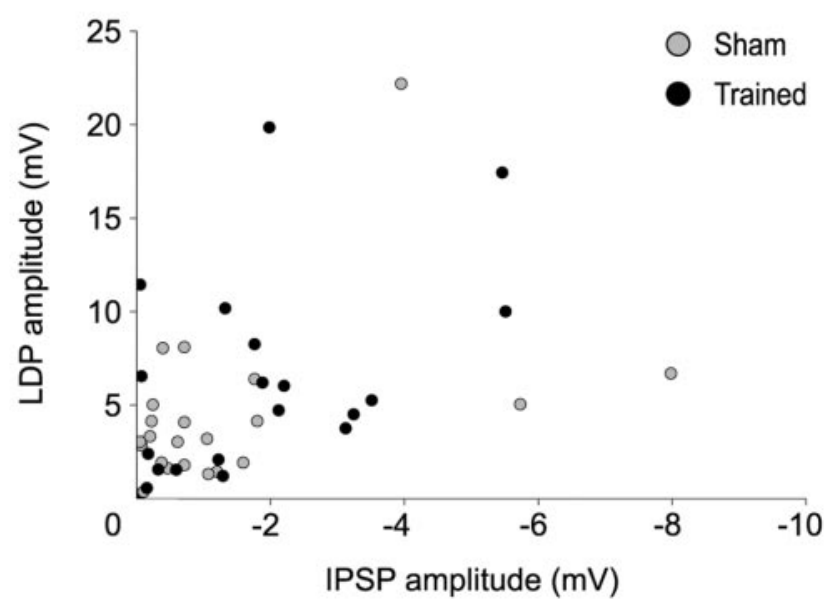

Figure 4. Training did not modify the phase dependency of cutaneous responses. $a, b$, PSPs recorded in MG motoneurons evoked by CCS stimuli during the depolarized (gray traces) and hyperpolarized (black traces) phases of the fictive step cycle in the sham $(a)$ and the trained cat $(b)$. The amplitude of the IPSP was decreased in the sham (by 50\%) and in the trained cat (by 92\%) during the hyperpolarized phase. c, IPSP amplitude was plotted against the LDP for all tested motoneurons in shams (gray) and trained cats (black). No linear relationship was observed between the two values neither in shams $(r=0.41)$ nor trained cats $(r=0.48)$. Mn, Motoneuron.

amplitude was significantly reduced by clonidine in this cell, as well as in the overall population (Fig. $5 c$ ).

Table 4 depicts the effect of clonidine on cutaneous responses. Among all the afferent-motoneuron pairs, we succeeded to test
65 of 72 . Of the 65 pathways tested at rest, five were significantly modified by clonidine in shams and two were significantly modified by clonidine in trained cats. The number of modified pathways in shams (two of seven) was not significantly different from the number of pathways in trained cats (five of seven). Overall, in shams, MPL-FHL-R1 amplitude was increased (Fig. 5a), and the amplitude of the following pathways was decreased: MPLFHL-R2 (Fig. 5a), CCS-MG-R1, CCS-MG-R3, and SP-Pl-R2. Overall, in trained cats, the amplitude of SP-FHL-R2 and SPMG-R2 was decreased (Fig. $5 a, c$ ). Interestingly, only pathways activated by SP afferents were significantly modified by clonidine in trained cats.

In contrast to training, clonidine more powerfully modified transmission in R2 pathways (four of seven). Clonidine was more likely to act on R2 not only to diminish its amplitude but also to reduce it to zero. Moreover, with clonidine there was significantly less occurrence of inhibition in two of four pathways: MPL-FHL in shams $(p<0.05)$ and SP-MG in trained cats $(p<0.01)$. No significant modification was observed in flexor/bifunctional motor pools of either sham or trained cats. Although clonidine and training both had a major influence on pathways to MG motoneurons (three of seven modified pathways), clonidine produced a supplementary effect on transmission in pathways to FHL motoneurons (three of seven).

We also assessed the additional effects of clonidine on statedependent changes in the transmission of cutaneous pathways by comparing responses obtained at rest and during fictive locomotion both in shams and in trained cats (Table 3b). Among all the possible afferent-motoneuron pairs, we succeeded in testing 14 in shams and 26 in trained cats. Additional locomotor-dependent changes attributable to clonidine were observed solely in 4 of 26 pathways in trained cats (Table 3b) and mostly for pathways from SP (2 of 3). Again, changes in transmission to MG motoneurons were the most frequent (two of three). Thus, once locomotor networks are activated (Table 3a) (17 modified pathways), the effect of clonidine per se is minimal (4 modified pathways).

We finally assessed the effect of clonidine on state-dependent changes in shams and trained cats that displayed locomotor episodes before and after clonidine injection. Of the 23 pathways tested, clonidine significantly decreased inhibitory transmission in only one pathway in shams: CCS-MG-R2.

\section{Discussion}

\section{Plasticity in spinal pathways}

It is now recognized that reflex pathways exhibit plasticity in response to central or peripheral lesions or operant conditioning (Mendell, 1984; Durkovic, 1996;Wolpaw and Tennissen, 2001). Recovery of function may occur after spinal lesion; however, the role of plastic reflex pathways underlying the recovery remains to be defined.

The preparation in this study (i.e., acute experiments in curarized animals) allows stable intracellular recordings of responses in motoneurons that are not influenced by rhythmic sensory feedback. The effect of training can therefore be attributed to changes occurring in spinal pathways and not to alterations in peripheral sensory events or muscle properties (Roy and Acosta, 1986; Roy et al., 1999). Changes in cutaneous reflexes have been previously attributed to specific alterations in premotoneuronal mechanisms and not to changes in passive membrane properties of motoneurons between acute and chronic spinal cats (Chandler et al., 1984; Munson et al., 1986; Baker and Chandler, 1987a). Moreover, modified properties of motoneurons could not explain increased monosynaptic reflexes in chronic spinal animals 
(Hochman and McCrea, 1994). In this study, training did not modify AHP duration, which varies with input resistance and membrane time constant (Gustafsson and Pinter, 1984; Côté et al., 2003). Moreover, a general change in membrane responsiveness is unlikely to explain the simultaneous increase in R1 amplitude and decrease in R3 amplitude observed in the same motoneuron (Table 2). We therefore consider that most of the plasticity after step training resulted from interneuronal mechanisms. However, a complete investigation of motoneuronal properties after chronic spinalization and step training is clearly needed to understand their contribution to the plasticity of sensory transmission. Latencies of cutaneous responses in hindlimb motoneurons are minimally trisynaptic (Lundberg et al., 1977; Baker and Chandler, 1987b; Fleshman et al., 1988; LaBella et al., 1989; LaBella and McCrea, 1990), and such linkage is appropriate for R1 responses in this study. There is an exceptional disynaptic linkage between SP and FDL motoneurons during the depolarized phase of fictive stepping in decerebrate cats (cf. Burke, 1999). Later responses (R2 and R3) most probably involve longer chains of spinal interneurons, the exact number of which is precarious to estimate.

Previous work suggested that removal of cutaneous inputs does not exert an important effect on rhythm generation in intact quadrupeds because they may use alternative inputs to compensate (Sherrington, 1910; Forssberg et al., 1977; Duysens and Stein, 1978). However, in spinal cats, at least one source of cutaneous information is necessary to recover proper foot placement during stepping (Bouyer and Rossignol, 2003a,b). In this study, we present experimental evidence that step training induced robust plasticity in the transmission of particular cutaneous pathways that was apparent at rest, without neuromodulators or locomotor network configuration. Moreover, the results show that the addition of clonidine or the activity of locomotor networks induced additional changes in cutaneous transmission, most of them in shams (see above). This study therefore supports the idea that cutaneous feedback from the hindlimbs is important for the full expression of locomotion after spinal transection.

Cutaneous transmission was modified by training only in a few specific pathways ( 10 of 71), transmission being decreased in the majority ( 7 of 10). The changes observed may represent training-related plasticity superimposed on spinalizationinduced plasticity or a removal or prevention of spinalizationinduced plasticity. For example, there is a persistent hyperexcitability of several reflexes following SCI because of the removal of inhibitory descending inputs from the brainstem (Holmqvist and Lundberg, 1961; Lundberg, 1964; Hultborn and Malmsten, 1983). A recent study showed that some flexor reflex components mediated by thick sensory afferents increased permanently their excitability after SCI in rats (Malmsten, 1983; Valero-Cabré et al., 2004). A similar hyperexcitability seen in withdrawal reflexes would contribute to spasms and spasticity (Ashby and McCrea, 1987; Bennett et al., 1999; Rémy-Néris et al., 1999). Thus, because chronic spinalization induces an enhanced cutaneous reflex re-
Table 4. Effect of clonidine on the mean amplitude of responses in specific cutaneous pathways

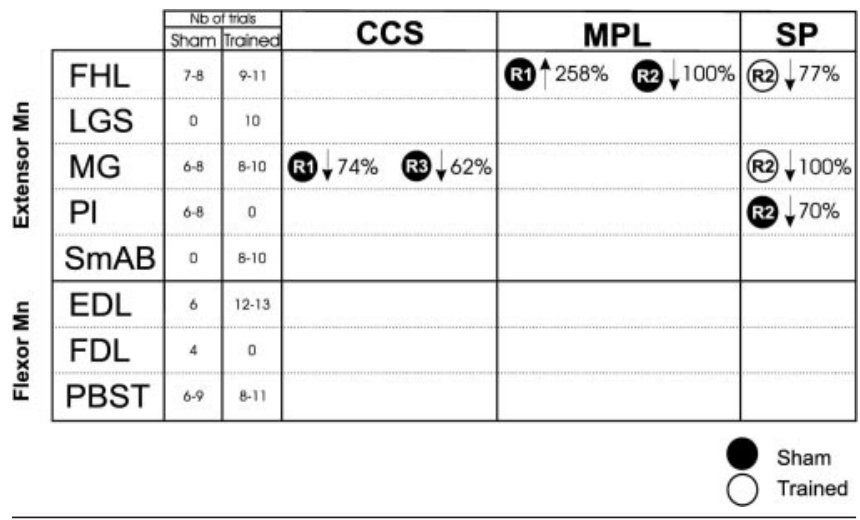

Same display as in Table 2. The effect of clonidine is reported according to the afferents (CCS, MPL, and SP) and motoneurons (FHL, LGS, MG, PI, SmAB, EDL, FDL, and PBSt). Pathways (R1, R2, or R3) significantly modified by clonidine ( 7 of 65 tested pathways) are represented as filled circles in shams and as empty circles in trained cats. The percentage is calculated by comparing the mean amplitude obtained after clonidine to the one obtained before clonidine. The number of trials for each pathway in the corresponding motor pool is reported in the second (sham) and third (trained) columns. A zero indicates that there was not enough data to perform statistical tests in that group.

sponsiveness, step training may compensate for this by normalizing the level of cutaneous transmission. In such a case, the comparison between trained and untrained spinal cats would show up as a decrease in cutaneous transmission.

\section{Plasticity in cutaneous pathways is highly specific}

Training alone evoked modifications in 10 of 71 pathways involving three of three tested cutaneous nerves and four of eight motor 
pools. The comparison of responses from the vast majority of the other pathways between the two groups was far from reaching statistical significant difference ( 54 of $61 ; p>0.1$ ). We therefore believe that these changes represent a true task-specific plasticity in cutaneous transmission (DeLeon et al., 1998b, 1999). It is not known whether longer periods of step training or a larger sample would have revealed changes in additional pathways. Nervespecific reflex responses to cutaneous stimulation were previously observed during locomotion in cats (Abraham et al., 1985; Moschovakis et al., 1991; Pratt et al., 1991; LaBella et al., 1992; Degtyarenko et al., 1996) and humans (van Wezel et al., 1997) to provide location-specific information from the skin of the foot. However, a common synergy of flexor responses in the swing phase and of extensor responses in the stance phase was also observed, independent of the location of the stimulus in cats walking on a treadmill (Duysens and Stein, 1978; Duysens and Loeb, 1980; Abraham et al., 1985). Thus, during locomotion, both common and nerve-specific controls of cutaneous reflex responses were observed. Our results did show specificity but no simple swing- or stance-related patterns during fictive stepping.

Clonidine markedly reduces cutaneous excitability while accelerating the recovery of stepping in spinal cats (Barbeau et al., 1987; Chau et al., 1998a,b). Here clonidine was not used during training but only during the acute experiment to facilitate the emergence of fictive stepping (Pearson and Rossignol, 1991). As expected, when significantly modified by clonidine, transmission in cutaneous pathways was decreased in all cases but one (Table 4). It is remarkable that clonidine modified pathways mostly in shams (five of seven). This is surprising because we expected training to favor the responsiveness of spinal networks to clonidine (Côté et al., 2003). An alternative interpretation for these findings is that both training and clonidine target the same pathways so that clonidine only added a small effect because training already decreased cutaneous transmission. We may further speculate that some cutaneous reflexes are detrimental to recovery of stepping and that clonidine or step training is a different mean to normalize the cutaneous feedback onto spinal locomotor networks.

Recent studies (Edgerton et al., 2001; Tillakaratne et al., 2002) reported that a complete spinal section in cats increased levels of GABA and glycine in spinal tissues and that step training (but not stand training) decreased these levels toward normal values. Our results showed that only 2 of 10 (Table 2, R2) inhibitory cutaneous pathways were modified by step training, so global changes in inhibitory systems may be affecting other pathways.

\section{Possible role of modified cutaneous transmission}

A major finding is that training predominantly modified transmission in pathways to MG motoneurons, particularly when activated by MPL afferents. MG is an ankle extensor muscle involved in weight support during stance. The plantar surface of the foot (MPL receptive field) presumably provides phasic information about the ground surface. Previous studies show that extensor reflexes evoked by the plantar surface of the foot can promote extension during stance and stop the swing phase of locomotion (Duysens and Pearson, 1976; Duysens, 1977; Guertin et al., 1995). Our results indicate that both training (Table 2) and fictive locomotion in shams (Table 3a) result in a net excitatory action from MPL to MG motor pool. Thus, we suggest that at least some of the modified pathways would result in a better recruitment of the MG pool during ground contact that may help to recover weight bearing.

Our study also showed there was no remarkable change in the distribution of types of motoneuronal responses after training. Step training is therefore upregulating or downregulating transmission in existing pathways. However, a significant change in transmission to FDL motoneurons was observed (all cutaneous nerves pooled together): going from type A to type D response (i.e., without inhibition, R2). FDL is a toe plantar flexor active just at the onset of swing (Fleshman et al., 1984; Schmidt et al., 1988; Moschovakis et al., 1991; Degtyarenko et al., 1996) to clear the toes from the ground (as St burst) (Rossignol, 1996). We suggest that inhibitory transmission to FDL is decreased in general to facilitate the excitatory effects of cutaneous signals related to paw drag during early training sessions. Together with the increase in transmission in the MPL-PBSt-R3 excitatory pathway, this would result in a better clearing of the toes at the onset of swing.

However, it is difficult to interpret the exact role of modified cutaneous transmission in the control or recovery of locomotion, because there is little understanding of its role in normal locomotion. For example, some receptors from the plantar surface of the foot were found to fire during swing and to be silent during stance (Loeb et al., 1977). Thus, the influence of cutaneous inputs on spinal pathways in a particular phase of stepping cannot be predicted solely based on its anatomical localization.

\section{Load or skin?}

Proprioceptive inputs can act directly on the CPG, particularly those evoked by group I afferents from extensors (Conway et al., 1987; Gossard et al., 1994; McCrea, 1998; Pearson et al., 1998). Our recent experiments demonstrated that step training decreased group IB inhibition and increased polysynaptic group I excitation of extensors after clonidine injection in spinal cats, suggesting a better recruitment of antigravity muscles to assist the recovery of weight bearing (Côté et al., 2003). Cutaneous inputs do not have such a powerful action on rhythm generation, and we therefore expected less plasticity in these pathways than in proprioceptive pathways. However, significant changes in cutaneous transmission could be seen even without clonidine or fictive locomotion. The plasticity in cutaneous pathways was therefore more robust than in group I pathways studied in the same animals (Côté et al., 2003). The relative contribution of different sensory modalities for the recovery of stepping after SCI is still unclear. This knowledge is necessary to focus and improve training strategies in SCIs (Dietz et al., 2002; Ferris et al., 2004).

\section{References}

Abraham LD, Marks WB, Loeb GE (1985) The distal hindlimb musculature of the cat. Cutaneous reflexes during locomotion. Exp Brain Res 58:594-603.

Andersson O, Forssberg H, Grillner S, Lindquist M (1978) Phasic gain control of the transmission in cutaneous reflex pathways to motoneurones during "fictive" locomotion. Brain Res 149:503-507.

Ashby P, McCrea DA (1987) Neurophysiology of spinal spasticity. In: Handbook of the spinal cord (Davidoff RA, ed), pp 120-143. New York: Dekker.

Baker LL, Chandler SH (1987a) Characterization of hindlimb motoneuron membrane properties in acute and chronic spinal cats. Brain Res 420:333-339.

Baker LL, Chandler SH (1987b) Characterization of postsynaptic potentials evoked by sural nerve stimulation in hindlimb motoneurons from acute and chronic spinal cats. Brain Res 420:340-350.

Barbeau H, Rossignol S (1987) Recovery of locomotion after chronic spinalization in the adult cat. Brain Res 412:84-95.

Barbeau H, Rossignol S (1991) Initiation and modulation of the locomotor pattern in the adult chronic spinal cat by noradrenergic, serotonergic and dopaminergic drugs. Brain Res 546:250-260.

Barbeau H, Julien C, Rossignol S (1987) The effects of clonidine and yohim- 
bine on locomotion and cutaneous reflexes in the adult chronic spinal cat. Brain Res 437:83-96.

Bennett DJ, Gorassini M, Fouad K, Sanelli L, Han Y, Cheng J (1999) Spasticity in rats with sacral spinal cord injury. J Neurotrauma 16:69-84.

Bouyer LJ, Rossignol S (2003a) Contribution of cutaneous inputs from the hindpaw to the control of locomotion. I. Intact cats. J Neurophysiol 90:3625-3639.

Bouyer LJ, Rossignol S (2003b) Contribution of cutaneous inputs from the hindpaw to the control of locomotion. II. Spinal cats. J Neurophysiol 90:3640-3653.

Burke RE (1999) The use of state-dependent modulation of spinal reflexes as a tool to investigate the organization of spinal interneurons. Exp Brain Res 128:263-277.

Chandler SH, Baker LL, Goldberg LJ (1984) Characterization of synaptic potentials in hindlimb extensor motoneurons during L-DOPA-induced fictive locomotion in acute and chronic spinal cats. Brain Res 303:91-100.

Chau C, Barbeau H, Rossignol S (1998a) Early locomotor training with clonidine in spinal cats. J Neurophysiol 79:392-409.

Chau C, Barbeau H, Rossignol S (1998b) Effects of intrathecal $\alpha_{1^{-}}$and $\alpha_{2^{-}}$ noradrenergic agonists and norepinephrine on locomotion in chronic spinal cats. J Neurophysiol 79:2941-2963.

Conway BA, Hultborn H, Kiehn O (1987) Proprioceptive input resets central locomotor rhythm in the spinal cat. Exp Brain Res 68:643-656.

Coombs JS, Eccles JC, Fatt P (1955) The specific ionic conductances and the ionic movements across the motoneuronal membrane that produce the inhibitory post-synaptic potentials. J Physiol (Lond) 130:326-373.

Côté MP, Ménard A, Gossard JP (2003) Spinal cats on the treadmill: changes in load pathways. J Neurosci 23:2789-2796.

Degtyarenko AM, Simon ES, Burke RE (1996) Differential modulation of disynaptic cutaneous inhibition and excitation in ankle flexor motoneurons during fictive locomotion. J Neurophysiol 76:2972-2985.

DeLeon RD, Hodgson JA, Roy RR, Edgerton VR (1998a) Locomotor capacity attributable to step training versus spontaneous recovery after spinalization in adult cats. J Neurophysiol 79:1329-1340.

DeLeon RD, Hodgson JA, Roy RR, Edgerton VR (1998b) Full weightbearing hindlimb standing following stand training in the adult spinal cat. J Neurophysiol 80:83-91.

DeLeon RD, Tamaki H, Hodgson JA, Roy RR, Edgerton VR (1999) Hindlimb locomotor and postural training modulates glycinergic inhibition in the spinal cord of the adult spinal cat. J Neurophysiol 82:359-369.

Dietz V, Muller R, Colombo G (2002) Locomotor activity in spinal man: significance of afferent input from joint and load receptors. Brain $125: 2626-2634$

Drew T, Rossignol S (1987) A kinematic and electromyographic study of cutaneous reflexes evoked from the forelimb of unrestrained walking cats. J Neurophysiol 57:1160-1184.

Durkovic RG (1996) The spinal cord: a simplified system for the study of neural mechanisms of mammalian learning and memory. In: Development and plasticity of the mammalian cord (Goldberger M, Gorio A, Murray M, eds), pp 149-162. New York: Springer.

Duysens J (1977) Reflex control of locomotion as revealed by stimulation of cutaneous afferents in spontaneously walking premammillary cats. J Neurophysiol 40:737-751.

Duysens J, Loeb GE (1980) Modulation of ipsi- and contralateral reflex responses in unrestrained walking cats. J Neurophysiol 44:1024-1037.

Duysens J, Pearson KG (1976) The role of cutaneous afferents from the distal hindlimb in the regulation of the step cycle of thalamic cats. Exp Brain Res 24:245-255.

Duysens J, Stein RB (1978) Reflexes induced by nerve stimulation in walking cats with implanted cuff electrodes. Exp Brain Res 32:213-224.

Duysens J, van Wezel BM, Prokop T, Berger W (1996) Medial gastrocnemius is more activated than lateral gastrocnemius in sural nerve induced reflexes during human gait. Brain Res 727:230-232.

Edgerton VR, Roy RR, Hodgson JA, Prober RJ, de Guzman CP, de Leon R (1992) Potential of adult mammalian lumbosacral spinal cord to execute and acquire improved locomotion in the absence of supraspinal input. J Neurotrauma 9:S119-S128.

Edgerton VR, De Leon RD, Tillakaratne N, Recktenwald MR, Hodgson JA, Roy RR (1997a) Use-dependent plasticity in spinal stepping and standing. Adv Neurol 72:233-247.

Edgerton VR, Roy RR, De Leon R, Tillakaratne N, Hodgson JA (1997b) Does motor learning occur in the spinal cord? Neuroscientist 3:287-294.
Edgerton VR, de Leon RD, Harkema SJ, Hodgson JA, London N, Reinkensmeyer DJ, Roy RR, Talmabge RJ, Tillakaratne NJ, Timoszyk W, Tobin A (2001) Retraining the injured spinal cord. J Physiol (Lond) 533:15-22.

Ferris DP, Gordon KE, Beres-Jones JA, Harkema SJ (2004) Muscle activation during unilateral stepping occurs in the nonstepping limb of humans with clinically complete spinal cord injury. Spinal Cord 42:14-23.

Fleshman JW, Lev-Tov A, Burke RE (1984) Peripheral and central control of flexor digitorum longus and flexor hallucis longus motoneurons: the synaptic basis of functional diversity. Exp Brain Res 54:133-149.

Fleshman JW, Rudomin P, Burke RE (1988) Supraspinal control of shortlatency cutaneous pathway to hindlimb motoneurons. Exp Brain Res 69:449-459.

Forssberg H, Grillner S (1973) The locomotion of the acute spinal cat injected with clonidine i.v. Brain Res 50:184-186.

Forssberg H, Grillner S, Rossignol S (1975) Phase dependent reflex reversal during walking in chronic spinal cats. Brain Res 85:103-107.

Forssberg H, Grillner S, Rossignol S (1977) Phasic gain control of reflexes from the dorsum of the paw during spinal locomotion. Brain Res 132:121-139.

Fung J, Barbeau H (1994) Effects of conditioning cutaneomuscular stimulation on the soleus $\mathrm{H}$-reflex in normal and spastic paretic subjects during walking and standing. J Neurophysiol 72:2090-2104.

Fung J, Stewart JE, Barbeau H (1990) The combined effects of clonidine and cyproheptadine with interactive training on the modulation of locomotion in spinal cord injured subjects. J Neurol Sci 100:85-93.

Giroux N, Rossignol S, Reader TA (1999) Autoradiographic study of $\alpha_{1}$ and $\alpha_{2}$-noradrenergic and serotonin ${ }_{1 \mathrm{~A}}$ receptors in the spinal cord of normal and chronically transected cats. J Comp Neurol 406:402-414.

Gossard JP, Brownstone RM, Barajon I, Hultborn H (1994) Transmission in a locomotor-related group Ib pathway from hindlimb extensor muscles in the cat. Exp Brain Res 98:213-228.

Guertin P, Angel MJ, Perreault M-C, McCrea DA (1995) Ankle extensor group I afferents excite extensors throughout the hindlimb during fictive locomotion in the cat. J Physiol (Lond) 487:197-209.

Gustafsson B, Pinter MJ (1984) Relations among passive electrical properties of lumbar alpha-motoneurones of the cat. J Physiol (Lond) 356:401-431.

Harkema SJ (2001) Neural plasticity after human spinal cord injury: application of locomotor training to the rehabilitation of walking. Neuroscientist 7:455-468.

Harkema SJ, Hurley SL, Patel UK, Requejo PS, Dobkin BH, Edgerton VR (1997) Human lumbosacral spinal cord interprets loading during stepping. J Neurophysiol 77:797-811.

Helgren ME, Goldberger ME (1993) The recovery of postural reflexes and locomotion following low thoracic hemisection in adult cats involves compensation by undamaged primary afferent pathways. Exp Neurol 123:17-34.

Hochman S, McCrea DA (1994) Effects of chronic spinalization on ankle extensor motoneurons. II. Motoneuron electrical properties. J Neurophysiol 71:1468-1479.

Holmqvist B, Lundberg A (1961) Differential supraspinal control of synaptic actions evoked by volleys in the flexion reflex afferents in alpha motoneurones. Acta Physiol Scand 54:1-51.

Hultborn H, Malmsten J (1983) Changes in segmental reflexes following chronic spinal cord hemisection in the cat. I. Increased monosynaptic and polysynaptic ventral root discharges. Acta Physiol Scand 119:405-422.

LaBella LA, McCrea DA (1990) Evidence for restricted central convergence of cutaneous afferents on an excitatory reflex pathway to medial gastrocnemius motoneurons. J Neurophysiol 64:403-412.

LaBella LA, Kehler JP, McCrea DA (1989) A differential synaptic input to the motor nuclei of triceps surae from the caudal and lateral cutaneous sural nerves. J Neurophysiol 61:291-301.

LaBella LA, Niechaj A, Rossignol S (1992) Low-threshold, short-latency cutaneous reflexes during fictive locomotion in the "semi-chronic" spinal cat. Exp Brain Res 91:236-248.

Leblond H, Menard A, Gossard J-P (2000) Bulbospinal control of spinal cord pathways generating locomotor extensor activities in the cat. J Physiol (Lond) 525:225-240.

Leblond H, L'Esperance M, Orsal D, Rossignol S (2003) Treadmill locomotion in the intact and spinal mouse. J Neurosci 23:11411-11419.

Loeb GE, Bak MJ, Duysens J (1977) Long-term unit recording from so- 
matosensory neurons in the spinal ganglia of the freely walking cat. Science 197:1192-1194.

Lovely RG, Gregor RJ, Roy RR, Edgerton VR (1986) Effects of training on the recovery of full-weight-bearing stepping in the adult spinal cat. Exp Neurol 92:421-435.

Lundberg A (1964) Supraspinal control of transmission in reflex paths to motoneurones and primary afferents. Prog Brain Res 12:196-221.

Lundberg A, Malmgren K, Schomburg ED (1977) Cutaneous facilitation of transmission in reflex pathways from Ib afferents to motoneurones. J Physiol (Lond) 265:763-780.

Malmsten J (1983) Time course of segmental reflex changes after chronic spinal cord hemisection in the rat. Acta Physiol Scand 119:435-443.

McCrea DA (1998) Neuronal basis of afferent-evoked enhancement of locomotor activity. Ann NY Acad Sci 860:216-225.

McCrea DA, Shefchyk SJ, Stephens MJ, Pearson KG (1995) Disynaptic group I excitation of synergist ankle extensor motoneurones during fictive locomotion in the cat. J Physiol (Lond) 487:527-539.

Ménard A, Leblond H, Gossard JP (1999) The modulation of presynaptic inhibition in single muscle primary afferents during fictive locomotion in the cat. J Neurosci 19:391-400.

Mendell LM (1984) Modifiability of spinal synapses. Physiol Rev 64:260-324.

Moschovakis AK, Sholomenko GN, Burke RE (1991) Differential control of short latency cutaneous excitation in cat FDL motoneurons during fictive locomotion. Exp Brain Res 83:489-501.

Muir GD, Steeves JD (1997) Sensorimotor stimulation to improve locomotor recovery after spinal cord injury. Trends Neurosci 20:72-77.

Munson JB, Foehring RC, Lofton SA, Zengel JE, Sypert GW (1986) Plasticity of medial gastrocnemius motor units following cordotomy in the cat. J Neurophysiol 55:619-634.

Nacimiento W, Sappok T, Brook GA, Toth L, Schoen SW, Noth J, Kreutzberg GW (1995) Structural changes of anterior horn neurons and their synaptic input caudal to a low thoracic spinal cord hemisection in the adult rat: a light and electron microscopic study. Acta Neuropathol (Berl) 90:552-564.

Pearson KG, Rossignol S (1991) Fictive motor patterns in chronic spinal cats. J Neurophysiol 66:1874-1887.

Pearson KG, Misiaszek JE, Fouad K (1998) Enhancement and resetting of locomotor activity by muscle afferents. Ann NY Acad Sci 860:203-215.

Pinter MJ, Burke RE, O’Donovan MJ, Dum RP (1982) Supraspinal facilitation of cutaneous polysynaptic EPSPs in cat medical gastrocnemius motoneurons. Exp Brain Res 45:133-143.
Powers RK, Binder MD (1985) Distribution of oligosynaptic group I input to the cat medial gastrocnemius motoneuron pool. J Neurophysiol 53:497-517.

Pratt CA, Chanaud CM, Loeb GE (1991) Functionally complex muscles of the cat hindlimb. IV. Intramuscular distribution of movement command signals and cutaneous reflexes in broad, bifunctional thigh muscles. Exp Brain Res 85:281-299.

Rémy-Néris O, Barbeau H, Daniel O, Boiteau F, Bussel B (1999) Effects of intrathecal clonidine injection on spinal reflexes and human locomotion in incomplete paraplegic subjects. Exp Brain Res 129:433-440.

Rossignol S (1996) Neural control of stereotypic limb movements. In: Handbook of physiology, Sec 12, Exercise: regulation and integration of multiple systems (Rowell LB, Sheperd JT, eds), pp 173-216. Oxford: American Physiological Society.

Roy RR, Acosta L (1986) Fiber type and fiber size changes in selected thigh muscles six months after low thoracic spinal cord transection in adult cats: exercise effects. Exp Neurol 92:675-685.

Roy RR, Talmadge RJ, Hodgson JA, Oishi Y, Baldwin KM, Edgerton VR (1999) Differential response of fast hindlimb extensor and flexor muscles to exercise in adult spinalized cats. Muscle Nerve 22:230-241.

Schmidt BJ, Meyers DE, Fleshman JW, Tokuriki M, Burke RE (1988) Phasic modulation of short latency cutaneous excitation in flexor digitorum longus motoneurons during fictive locomotion. Exp Brain Res 71:568-578.

Schomburg ED, Behrends HB (1978) Phasic control of the transmission in the excitatory and inhibitory reflex reflex pathways from cutaneous afferents to alpha-motoneurones during fictive locomotion in cats. Neurosci Lett 8:277-282.

Sherrington CS (1910) Flexion-reflex of the limb, crossed extension reflex, and reflex stepping and standing. J Physiol (Lond) 40:28-121.

Tillakaratne NJK, DeLeon R, Hoang TX, Roy RR, Edgerton VR, Tobin AJ (2002) Use-dependent modulation of inhibitory capacity in the feline lumbar spinal cord. J Neurosci 22:3130-3143.

Valero-Cabré A, Fores J, Navarro X (2004) Reorganization of reflex responses mediated by different afferent sensory fibres after spinal cord transection. J Neurophysiol 91:2838-2848.

van Wezel BM, Ottenhoff FA, Duysens J (1997) Dynamic control of location-specific information in tactile cutaneous reflexes from the foot during human walking. J Neurosci 17:3804-3814.

Wolpaw JR, Tennissen AM (2001) Activity-dependent spinal cord plasticity in health and disease. Annu Rev Neurosci 24:807-843. 